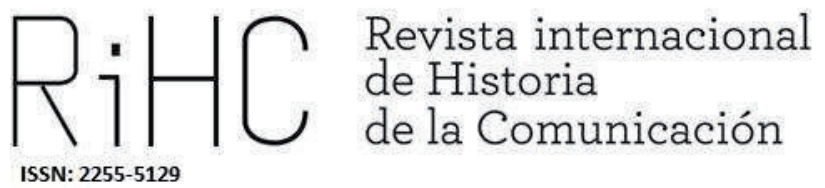

\title{
MUJERES CORRESPONSALES EN EL FRANQUISMO: LOS CASOS DE PILAR NARVIÓN Y CONCHITA GUERRERO
}

Correspondent women during Francoism: the cases of Pilar Narvión and Conchita Guerrero

DOI: http://dx.doi.org/10.12795/RiCH.2021.i16.06

Clara Sanz-Hernando

Universidad de Extremadura, España

clarasanz@unex.es

ORCID (ID https://orcid.org/0000-0003-3127-8876

Helena Lima

Universidad de Oporto, Portugal

hllima@letras.up.pt

ORCID (i) http://orcid.org/0000-0003-3023-6412 
Resumen: El trabajo profundiza en dos periodistas pioneras durante el franquismo: Pilar Narvión y Concepción López Guerrero, conocida en el mundo periodístico como Conchita Guerrero. Corresponsales del diario Pueblo: en Roma y París, la primera, y en Lisboa, la segunda, estuvieron al frente de esta información internacional durante los años cincuenta y sesenta hasta que regresaron en 1973 a la redacción madrileña, dirigida entonces por Emilio Romero. Pilar Narvión se convirtió en una reputada cronista parlamentaria y fue la primera mujer directora adjunta de un periódico. Conchita Guerrero llegó a ser jefa de la Sección de Internacional. Ambas, que compartieron su pasión por el periodismo político, permanecerían en el rotativo hasta su jubilación, en el caso de Narvión, y hasta su cierre por lo que se refiere a Guerrero. Con el empleo de una metodología cualitativa, y la utilización de fuentes bibliográficas, hemerográficas y de archivo, se profundiza en la vida de estas precursoras y se abordan sus trayectorias para entender la realidad que vivieron en la prensa de esta época y cómo sortearon los márgenes establecidos para la mujer por el régimen franquista.

Palabras clave: Mujer, prensa, franquismo, corresponsales, Pilar Narvión, Conchita Guerrero.

\begin{abstract}
The current research tackles two pioneering journalists during the Franco regime: Pilar Narvión and Concepción López Guerrero, known in the journalistic world with the alias Conchita Guerrero. They both were correspondents from the daily Pueblo, the first in Rome and Paris and the latter in Lisbon. They were in charge of international news during the fifties and sixties until they returned to Madrid, in 1973, when the newsroom was under Emilio Romero direction. Pilar Narvión became a reknowned parliamentary chronicler and became the first female deputy editor of a newspaper. Conchita Guerrero reached the head of the International Section. Both journalists shared a common passion for political journalism and both would remain in the newspaper until retirement, in Guerrero's case that would match the end of the Pueblo. The methodology will rely on a qualitative approach, a bibliographic review and the consultation of newspapers and archive sources that will provide means for portraying the pioneering experiences represented by these two journalists. This paper will explore their trajectories which are approached in order to understand the reality they lived as women from the press, in that particular time, and how they bypassed the margins established for feminine roles by the Franco regime.
\end{abstract}

Keywords: Woman, press, Francoism, correspondents, Pilar Narvión, Conchita Guerrero.

\title{
Introducción
}

Los cuarenta años de franquismo que se abrieron paso en España a partir de 1939 fueron resultado de la violenta acción contrarreformista y contrarrevolucionaria emprendida el 18 de julio de 1936 y que tuvo como objetivo frenar las importantes transformaciones políticas y sociales iniciadas durante la Segunda República (Casanova, 1992; Moradiellos, 2000). La dictadura se montó sobre la destrucción ideológica de todo lo anterior, cargó contra el liberalismo y la democracia, y tuvo una clara voluntad de arrasar con todo y de construir de nuevo (Juliá, 1999). 
Entre los principios ideológicos que sustentaron el nuevo Estado se impuso una moral social de carácter muy reaccionario y cuyas principales víctimas fueron las mujeres, a quienes se redujo al papel de madres y esposas. Volverían a definirse con rigidez dos esferas, la pública y la doméstica -plasmada en el hogar, el matrimonio y la maternidad (Cenarro, 2017; Establier, 2000)-, y las mujeres volvieron otra vez a su posición anterior a 1931, o a una situación peor, porque no quedó ni rastro de los movimientos feministas que habían emergido ya en los últimos años de la Restauración ni de las conquistas legales logradas antes de la etapa republicana.

Por lo que al régimen de prensa se refiere, experimentó una ruptura drástica con respecto a la prensa heredada de la República. El instrumento para someter a los medios de comunicación y convertirlos en "institución nacional" fue la Ley de Prensa de 1938, a través de la que se produjo el control periodístico más restrictivo en la historia de España (Barrera, 1995; Chuliá, 2001). La norma estuvo en vigor casi 30 años, hasta que fue sustituida por la Ley de Prensa e Imprenta de 1966, que introdujo tres novedades: la libertad de expresión, la eliminación de la censura previa y la libertad de empresa. Pese a su retórica liberalizante en los derechos que reconocía, lo cierto es que seguía siendo propia de la dictadura franquista. No obstante, supuso una renovación en la prensa española y abrió el camino hacia la apertura informativa (Seoane y Saiz, 2007). Los diarios se convirtieron en una especie de parlamento paralelo, de foro de intercambio de ideas políticas, que llegaba hasta donde la arbitrariedad del ministro de Información les dejara. Algunos periodistas intentaron aprovechar esa "libertad a medias" (Barrera, 1995: 450) para ir ampliando progresivamente los límites de esa libertad de expresión.

\section{Mujeres periodistas y la conquista de la profesión}

Los estudios sobre la mujer y su acceso a la profesión periodística son múltiples y difieren en función del enfoque que se pretenda o de la experiencia de cada país. Esta investigación aborda la trayectoria de las periodistas Pilar Narvión y Concepción López Guerrero, que iniciaron su profesión en una etapa particularmente difícil, la dictadura española, por lo que resulta pertinente la perspectiva histórica y el marco contextual como antecedentes de este análisis. Nos centraremos, por tanto, en el periodismo femenino y en dos personalidades que construyeron su experiencia profesional en un período adverso, no solo por la ausencia de libertad de prensa, sino también por su condición de mujeres que se abrieron paso en una profesión tradicionalmente masculina. 
En la historia del periodismo, la mujer aparece vinculada a ejes específicos de actividad, a personalidades destacadas, a intelectuales relevantes o a quienes lucharon por una causa política. Es decir, los abordajes se afrontan desde una perspectiva excepcional más que en términos de profesionalización. No será por casualidad, ya que la prensa "It's a man's world!" (Kinnebrock, 2009: 107). Esta afirmación, que se refiere al estudio de los diarios del siglo XIX en Europa Central, bien podría entenderse en un sentido más global. En los orígenes de la actividad periodística, diferentes autores caracterizan la prensa del siglo XIX como un campo predominantemente masculino en el que el centro de las publicaciones fue el debate político y la lucha contra los regímenes de censura, siendo las publicaciones mayoritariamente ideológicas.

Con la industrialización, la prensa adoptará estrategias informativas más integrales desde el punto de vista de los temas, de la escritura, así como de los personajes en los que se centrarán las narrativas periodísticas, con mujeres protagonizando a menudo estas historias. De forma gradual irán apareciendo en los rotativos de información general asuntos dirigidos al público femenino, como la moda, la vida social y, por regla general, el ocio. En el caso de las revistas, surgieron cabeceras encaminadas fundamentalmente a mujeres en temáticas educativas, recreativas o religiosas que proliferaron en toda Europa (Bingham et al., 2018). Incluso en este período de transformación de la prensa, especialmente en la anglosajona, las mujeres llegaban a las redacciones de la mano de sus maridos o padres (Chambers y Steiner, 2010) y su colaboración contribuía a atraer nuevas audiencias, en una época de extraordinaria expansión para el periodismo.

Hasta mediados del siglo XX las periodistas estadounidenses y británicas tuvieron grandes dificultades para ganar espacio editorial y desarrollar los temas típicamente femeninos (Chambers y Steiner, 2010). El poder profesional de las mujeres en las democracias occidentales ha sido más evidente a partir de la década de los setenta, con la transformación del mercado de las noticias y el gran crecimiento de la televisión. Uno de los factores que acompañó su preponderancia en los medios de comunicación fue la mayor escolarización y profesionalización de las periodistas, en una tendencia identificada por distintos autores y países (Rieffel, 2003; Subtil, 2009; Djerf-Pierre, 2007). La conquista de las redacciones fue un proceso largo, marcado por diferentes obstáculos, y no solo porque las mujeres tuvieran una peor consideración en una profesión marcadamente masculina. Los regímenes políticos y los entornos socioculturales limitaron su papel en varios frentes, y el periodismo no fue ajeno a este orden establecido.

La presencia femenina en los diarios españoles fue más tardía, y ello porque el nacimiento del periodismo moderno en España no tendría lugar hasta mediados del siglo XIX (Pizarroso, 2010). Las periodistas españolas, al compararlas con el número de las existentes en EEUU, Francia o Reino Unido, eran escasas, aunque se dieran 
tempranas colaboraciones, generalmente literarias. El catálogo del siglo XX de López de Zuazo plasma (Díaz Nosty, 2020) la escasa incorporación de las periodistas del periodo republicano, si bien su porcentaje se multiplicó por algo más de siete con respecto a las registradas en el catálogo de periodistas del siglo XIX de Ossorio y Bernard. Solo constituían el $12 \%$ de los registros. De los aproximadamente 15.000 profesionales considerados por el autor, en torno a 1.800 eran mujeres. Cabe recordar que, a comienzos del siglo XX, el $71 \%$ de la población femenina española no sabía ni leer ni escribir, frente a un 55\% de hombres analfabetos. La situación mejoró hacia 1930, cuando el analfabetismo femenino ya no llegaba al $40 \%$. No obstante, la mujer se encontraba en una clara desventaja, pues eran muy pocas quienes accedían a la Universidad (Fusi, 2012).

Carmen de Burgos Seguí, que firmaba bajo el seudónimo de Colombine (Almería 1867Madrid 1932), fue la primera mujer periodista profesional en España. Junto a Emilia Pardo Bazán (La Coruña 1851-Madrid 1921), figura en los primerísimos puestos de la profesión. Fue también pionera en cubrir una guerra -firmó en 1909 desde Melilla varias crónicas sobre la Guerra del Rif-. Escribió sobre la discriminación de la mujer en las leyes y en la sociedad; se mostró partidaria del divorcio y el voto femenino, y luchó por la implantación de la República (Castañeda, 1994; Núñez, 1991; 2005; Palomo, 2010). En el contexto de la llegada de la Segunda República en 1931 surgió Josefina Carabias, la primera mujer que hizo periodismo tal y como lo conocemos. Ha sido referente de muchas periodistas españolas. Al igual que Carmen de Burgos, Carabias hizo reportajes y encuestas sobre el voto femenino y la pena de muerte, entrevistó a las mujeres del momento como Victoria Kent y a los hombres de la República (García-Albi, 2007; Torres, 2016).

Al menos 12 periodistas republicanas y franquistas cubrieron los distintos escenarios bélicos de la Guerra Civil, con una presencia en el bando republicano muy superior al insurrecto. En este periodo, cuando se produjo la llegada a España de más de 50 reporteras y colaboradoras de prensa extranjera de 20 nacionalidades, tuvo lugar un hecho relevante, y es que por primera vez las mujeres dirigieron diarios de información general en España: María Luz Morales, La Vanguardia (Barcelona); Regina García, La Voz (Madrid); Anna Murià, Diari de Catalunya (Barcelona) y Matilde Zapata, La Región (Santander). Esta última, junto con otras como Juanita Mir, en Bilbao, y María Domínguez, en Fuendejalón, Zaragoza, serían ejecutadas. Un elevado número de redactoras fueron, además, depuradas y exiladas (Díaz Nosty, 2020).

El papel estelar de tantas periodistas durante la Segunda República enmudeció de forma abrupta a partir de 1939. Las pocas mujeres que dieron el relevo fueron afines al nuevo régimen o se orientaron, básicamente, hacia revistas destinadas al público femenino. El Registro Oficial de Periodistas, previsto en la Ley de Prensa de 1938, fue el último filtro que el régimen utilizó para depurar a los periodistas que habían trabajado en zona roja. 
La profesión quedó encuadrada también (Chuliá, 2001) a través de la creación de la Escuela Oficial de Periodismo, centro académico cuyos estudios capacitaban para la obtención del título de periodista. La Escuela cesó su actividad en diciembre de 1975, tras 34 años de funcionamiento, al incorporarse los estudios de Periodismo a la Universidad. Ángel Benito (1969) considera que la etapa que comprendería desde su creación, el 17 de septiembre de 1941, hasta la formación del Ministerio de Información y Turismo en 1951, fue un "instrumento de control" para seleccionar a los profesionales, mientras que la etapa siguiente tuvo "un tono abiertamente positivo".

De la Escuela Oficial de Periodismo salieron 25 promociones (Aguinaga, 1982), a las que hay que añadir las tres de la Escuela Oficial de Periodismo de Barcelona, las 12 de la Escuela de Periodismo de la Iglesia, y otras 12 del Instituto de Periodismo de Navarra. En conjunto, estos centros licenciaron a 3.903 estudiantes. De estos, el profesor Aguinaga identificó con nombres y apellidos a 3.190, lo que nos ha permitido conocer que el número de mujeres ascendía a 678 (21,20\%). La presencia femenina comenzó a crecer a partir de 1955, si bien a cuentagotas y con importantes altibajos, siendo la última promoción 1974/1975 la que experimentó la mayor cifra de tituladas (147). Como puede advertirse, las graduadas en Periodismo durante la dictadura fueron pocas, si bien con el nacimiento de las facultades de Ciencias de la Información, en coincidencia con la Transición política, los porcentajes entre hombres y mujeres se equipararon y, en muy poco tiempo, reflejaron la superioridad numérica femenina (Díaz Nosty, 2020). Este incremento tuvo su reflejo en las redacciones de los periódicos, donde las mujeres fueron incorporándose durante la Transición y ya, de forma imparable, con la llegada de la democracia (Carrasco y Moreno, 2019). En los 80 crecerá de forma exponencial la visibilidad de la mujer como productora de información en las páginas de los diarios. Aunque sus firmas fueron predominantes en las denominadas secciones blandas, consideradas de menos prestigio y destinadas a temas de ocio o de interés humano, comenzarán a asomar igualmente en las secciones duras, fundamentalmente política y economía.

\section{Objetivos y metodología}

El objetivo de este artículo es abordar las trayectorias profesionales de dos periodistas pioneras durante el franquismo: Pilar Narvión (Alcañiz 1922-Madrid 2013) y Concepción López Guerrero (Melilla 1920-Madrid 2020), conocida en el mundo periodístico como Conchita Guerrero. Fueron corresponsales del diario Pueblo: en Roma y París, la primera, y en Lisboa, la segunda. Ambas, que compartieron su pasión por el periodismo político, permanecerían en el rotativo hasta su jubilación, en el caso de Narvión, y hasta 
su cierre, con relación a Guerrero, que se incorporaría después al Gabinete de Prensa del Ministerio del Interior.

La oportunidad de esta investigación radica en la ausencia de estudios sobre Conchita Guerrero y en la necesidad de seguir profundizando en el desarrollo profesional de Pilar Narvión. Estas periodistas desempeñaron igual tarea, ejercieron en el mismo rotativo y compartieron idéntica época. No obstante, y a pesar de estas coincidencias, la evolución de sus carreras profesionales fue dispar. Interesa, pues, ahondar en la vida de estas precursoras, cuya niñez estuvo marcada por la Guerra Civil; comprobar cómo se produjo su acceso al periodismo en una etapa de absoluta subordinación del rol de la mujer, y visibilizar el trabajo que desempeñaron.

Se emplea una metodología cualitativa, con entrevistas en profundidad a Elena Lizón, hija de Conchita Guerrero -27 de noviembre de 2020-, y a Javier Capitán, sobrino de Pilar Narvión -3 de febrero de 2021-. La utilización de fuentes orales ha sido crucial para construir la biografía de Conchita Guerrero y arrojar luz sobre las limitadas publicaciones relativas a Pilar Narvión. Además de la consulta bibliográfica y hemerográfica, se ha accedido a los archivos familiares de las cronistas, así como a los fondos documentales de la Asociación de la Prensa de Madrid, organización a la que pertenecieron y donde se custodian sus expedientes profesionales.

\section{El acceso a la profesión}

Pilar Narvión fue la primera mujer que trabajó en el diario Pueblo. Se incorporó en 1950, cuando lo dirigía Juan Aparicio, a la sazón director de la Escuela Oficial de Periodismo. Los orígenes de este periódico vespertino se remontan al final de la Guerra Civil, cuando en 1940 la Delegación Nacional de Sindicatos incautó los talleres y la maquinaria de la antigua publicación socialista Claridad, propiedad de Luis Arasquistán (Guzmán, 1982). Integrado administrativamente en la Prensa del Movimiento, fue portavoz de los temas propios del llamado sindicato vertical. Emilio Romero fue nombrado director en 1952. Gracias a los cambios que introdujo, dotando a la información de una gran dosis de populismo y con un cambio radical del diseño, mucho más atractivo y ágil, logró convertirse en el tercer diario más leído en los años setenta, por detrás de La Vanguardia y $A B C$. Romero abandonó la dirección en 1975, año en el que fue nombrado delegado nacional de Prensa y Radio del Movimiento. Durante la Transición, Pueblo pasó a depender de los Medios de Comunicación Social del Estado. Su cierre, en 1984, está ligado a la llegada de la democracia, a la pérdida de lectores y a la desaparición de la ayuda económica de la cuota sindical (Davara, 2005). 
La pasión de Pilar Narvión por el periodismo (Ventero, 2008) comenzó a los 7 años, cuando ayudaba a su tío Mariano Romance, propietario y director de Amanecer (Alcañiz, Teruel), a enviar el diario a los suscriptores. A los 13 años colaboraba ya en la revista Domingo, donde publicaba semanalmente, y en contraportada, la novela corta La herencia de Míster Pepe. Cuando a los 17 años visitó la redacción de esta publicación, ubicada en Madrid, el redactor jefe se quedó "estupefacto". "No podía imaginarse que fuera una cría", según aseguraba Narvión (Soriano, 2008: 29). Aquel día el director de Domingo la animó a estudiar periodismo.

Cuando en 1947 intentó matricularse en la Escuela Oficial de Periodismo, el curso ya había comenzado, por lo que, en lugar de echarse atrás, escribió al director solicitando su ingreso. En dicha carta, exponía que su vocación había surgido en el periódico de su tío, Mariano Romance, argumento que constituyó el aval suficiente para que Juan Aparicio, "que se conocía a todos los periodistas de España" (Soriano, 2008: 34), permitiera que comenzara las clases ese mismo curso. Años después, sería también el propio Aparicio quien la incorporó a Pueblo, pues en su doble condición de director de la Escuela de Periodismo y del vespertino, contaba con los alumnos que más le convencían. Su llegada al rotativo causó expectación y la advertencia de que quedaban desterradas las "palabrotas y los chistes verdes" (Soriano, 2008: 71). Al principio, solo acudía a la redacción para llevar su crónica, pero en 1952 la hicieron colaboradora fija y el 1 de mayo de 1954 promocionó a redactora, con un sueldo mensual de 1.870 pesetas. Ingresó en la Asociación de la Prensa de Madrid en junio de $1955^{1}$.

Por entonces, todo se hacía de forma artesanal y menos inmediata. Antes de que existieran los teletipos, las noticias de agencia llegaban a la sede del periódico a través de los cutilleros, una brigada de ciclistas que recogía las noticias de la agencia EFE y sus filiales Cifra y Alfil, y las llevaban hasta los periódicos a golpe de pedal. Entregaban las informaciones en sobres de colores: el azul para las procedentes de EFE, de carácter internacional; el marrón para Cifra, con nacional; y el verde para Alfil, con las noticias deportivas. Los sobres se dejaban en los casilleros de los abonados y los ciclistas de cada medio los recogían cada hora. Con el tiempo se recibieron en teletipo, lo que supuso "un paso de gigante" (Soriano, 2008: 51).

Durante estos años, y antes de que la destinaran de corresponsal a Roma, escribió una columna diaria en la contraportada bajo el epígrafe "Crónica mundana", denominada luego "Crónica de Madrid", donde daba cuenta de las cosas que sucedían en la capital. Por entonces, las periodistas trataban temas acordes con lo que se entendía que eran propios de su género: corazón, educación, cultura, moda, sociedad y frivolidades varias (García-Albi, 2007). Desde luego, política no.

\footnotetext{
${ }^{1}$ Expediente no 2518/1955. Pilar Narvión Royo. Asociación de la Prensa de Madrid.
} 
El aterrizaje de Conchita Guerrero al periodismo no se produjo a través de la Escuela Oficial, sino que llegó de la mano de Emilio Romero. De madre monárquica y padre republicano, vivió la Guerra Civil en Madrid mientras terminaba sus estudios de Bachillerato y asistía a clases particulares de francés, idioma que llegó a dominar desde esa época. Acabada la contienda, quiso ir a la Universidad y estudiar Filosofía y Letras, hecho que no fue posible al impedírselo su madre, quien consideraba que emprender estudios superiores "no era propio de señoritas" ${ }^{2}$. Aquello le dolió mucho, y cuando se trasladó a Lisboa cursó esta titulación, aunque no llegaría a concluirla. Asidua del Ateneo de Madrid, allí conoció al escritor Adolfo Lizón, con quien se casó a los 20 años. En 1944 la joven pareja se trasladó a Portugal al ser nombrado Lizón profesor de Literatura en el Instituto Español de Lisboa, cuyo director era Eugenio Montes.

Llegaron en los últimos meses de la Segunda Guerra Mundial, instalándose durante un año en un céntrico hotel donde se alojaban también muchos judíos huidos de la Alemania nazi que pretendían escapar a EE.UU. Posteriormente, se trasladaron a vivir a Estoril, a una casa cercana a Villa Giralda, la residencia de Don Juan de Borbón desde 1946. A principios de los 60 el matrimonio se afincó definitivamente en Lisboa.

Desde agosto de 1948, Adolfo Lizón compaginó su trabajo de profesor y escritor con el de corresponsal en Lisboa para la agencia Pyresa ${ }^{3}$, perteneciente a la cadena de Prensa del Movimiento. Como no sabía escribir a máquina, Conchita Guerrero le hacía las veces de secretaria. A la transcripción que ya realizaba de sus novelas, se añadieron ahora las de sus crónicas de prensa. En muchos casos, no se limitaba a copiarlas, sino que las redactaba imprimiendo su propio estilo. "Me acuerdo de discusiones en las que mi madre le reprochaba a mi padre el haber escrito esto o lo otro... realmente, la periodista era ella"4. Así fue como Conchita Guerrero fue introduciéndose en el periodismo.

A su gusto por la lectura -el poeta y filósofo Jesús Herrero la recuerda leyendo al mismo tiempo que hacía punto ${ }^{5}$-, se unía su afición por la escritura. Con frecuencia, escribía a sus amigos españoles contándoles con gran detalle el trascurrir de sus vidas en el país vecino. Algunas de esas cartas dirigidas a una de sus amigas llegaron un día a manos de Emilio Romero, quien poco tiempo después le ofreció la corresponsalía de Pueblo, trabajo que ejerció desde del 1 de marzo de $1955^{6}$.

\footnotetext{
${ }^{2}$ Elena Lizón, en discusión con las autoras, 27 de noviembre de 2020.

${ }^{3}$ Expediente no 2467/1951. Adolfo Lizón Gadea. Asociación de la Prensa de Madrid.

${ }^{4}$ Elena Lizón, en discusión con las autoras, 27 de noviembre de 2020.

${ }^{5}$ Carta de Jesús Herrero dirigida a la hija de Conchita Guerrero, Elena Lizón. 8 de septiembre de 2020.

${ }^{6}$ Expediente no 4577/1983. Concepción López Guerrero. Asociación de la Prensa de Madrid.
} 


\section{Corresponsales en el extranjero}

Para encontrar las primeras profesionales corresponsales durante el franquismo habrá que esperar hasta los años 50 (García-Albi, 2007), cuando los medios refuerzan la información internacional. Las noticias del exterior, aunque también sometidas a las consignas y limitadas inicialmente a los despachos de EFE, ofrecían un panorama más alentador que la aplastante homogeneidad que caracterizaba a las nacionales. En esta década, los periódicos que pudieron permitirse el uso de corresponsales fijos en el exterior dedicaron muchas más páginas a la información internacional que a la nacional (Pizarroso, 1989; Sanz-Hernando y Moreno, 2017), fenómeno que se mantuvo incluso en la última fase, más tolerante, del régimen.

Emilio Romero decidió dar un vuelco a Pueblo y hacer una gran campaña de corresponsales en 1956. Mandó a Manuel Blanco Tobío a Nueva York; a César Collazo a Londres; a Eugenia Serrano a Viena y a Pilar Narvión a Roma. En Bonn permaneció José María Carrascal; en Francia, Federico Madrid, y en Lisboa, Conchita Guerrero. A decir de Pilar Narvión, Romero fue el director de periódicos "más feminista de España", pues incorporó a la redacción el mayor número de mujeres y "cuando demostraban que podían hacer lo mismo que los hombres, les daba responsabilidades" (Soriano, 2008: 45). Las y los periodistas destacados en el extranjero eran por entonces las estrellas de los periódicos, pues sus informaciones, además de copar buena parte de las páginas de los diarios, se ubicaban en el lugar privilegiado de la portada. Las corresponsales de referencia para Narvión eran Josefina Carabias y Eugenia Serrano. De esta última se decía que escribía "como un hombre", lo que se interpretaba en aquella época como "halago supremo" (Soriano, 2008: 39).

Narvión dio cuenta desde Roma de los principales acontecimientos que transcurrían en Italia, que ya vivía en democracia tras la etapa fascista y la Segunda Guerra Mundial. “íbamos a cuerpo limpio. Toda tu corresponsalía eras tú y tu máquina de escribir explica Narvión-. Cuando había algo muy urgente llamabas por teléfono, si no lo mandabas por correo aéreo" (García-Albi, 2007: 161). Sus informaciones abarcaban desde política al mundo vaticano, sucesos o vida social. Comenzó a escribir crónicas parlamentarias, género en el que destacaría durante la última etapa de su vida profesional. El suceso más importante que cubrió fue la firma del Tratado de Roma, el 25 de marzo de 1957, que daría lugar a la creación de la nueva Europa. Allí se relacionó con periodistas españoles acreditados en la capital italiana y con compañeros de otros países que pertenecían a la Stampa Estera, el club de los corresponsales extranjeros.

Nueve meses después de la muerte de Pío XII, en enero de 1958, fue nombrada corresponsal en París. Allí conoció la creación de la $V$ Republica y el ascenso de Charles de Gaulle (1890-1970), cuyo tiempo presidencial completó en sus crónicas, y también el final de la guerra y la independencia de Argelia (1962), la revuelta estudiantil de mayo del 68 y la Conferencia de París sobre la guerra de Vietnam (1969) (Díaz Nosty, 2020). La 
corresponsalía de Pueblo en París trascendía las fronteras de Francia. A principios de los 60 viajó durante más de un mes por Dinamarca, Suecia, Finlandia y Noruega. Sus reportajes dejaron retratada la vida de los países escandinavos, que en España se tenían como paradigma de democracia y bienestar (Soriano, 2008). París supuso para Narvión el descubrimiento de la cultura en su sentido más amplio. Allí tuvo ocasión de relacionarse con la élite intelectual de la época y con políticos españoles en el exilio, como Santiago Carrillo.

Francia tenía mucho peso en la política internacional, de manera que Pilar Narvión enviaba crónicas políticas diarias y una de carácter cultural casi todas las semanas. Una de las cuestiones que más le sorprendió fue la cantidad de mujeres periodistas que cubrían la información. Además, cuando se encargó de informar sobre un proceso judicial relacionado con la guerra de Argelia, se asombró al ver los pasillos llenos de mujeres con toga y participando en los tribunales y en las defensas (García-Albi, 2007).

No era el caso de lo que sucedía por entonces en Lisboa, donde Conchita Guerrero no solo fue la única mujer periodista extranjera durante sus 18 años como corresponsal, sino que la presencia de las mujeres en las redacciones era, como en España, una rareza. La dictadura portuguesa, además de establecer un régimen represivo y de censura a la prensa, impidió también el desarrollo de la mujer en la sociedad. Carvalheiro y Silveirinha (2018) trazan un retrato de fuerte represión sobre el papel de la mujer, donde el sistema patriarcal era dominante y se complementaba con otros elementos restrictivos, entre ellos el sistema sociocultural y el propio discurso mediático. No sería hasta los años 60 cuando la profesión de periodista se abre a las mujeres en los diarios de información general (Ventura, 2012). Hasta entonces, ejercían principalmente en publicaciones especializadas o institucionales, donde se asociaba a las féminas con roles propios del hogar, o a través de colaboraciones puntuales en periódicos generalistas, a imagen de lo que sucedía al final de la Monarquía y principios de la Primera República.

Las redacciones portuguesas eran, pues, un mundo de hombres, pero los cambios que se produjeron en la prensa, sobre todo en los periódicos vespertinos, trajeron una mayor modernidad en la forma de hacer periodismo. La inclusión de la mujer en las redacciones en los años 60 y 70 es un indicador de esta modernización. Se incorporaron perfiles de periodistas con formación intelectual, siguiendo otros ejemplos europeos, muy distantes del modelo predominante de mujer confinada al espacio doméstico y al rol familiar. De igual forma, tuvieron espacio en las redacciones otras mujeres que fueron aliadas del régimen y que mantuvieron actitudes muy diferentes al de la generación que rompió barreras.

Conchita Guerrero compatibilizó la corresponsalía en Pueblo con colaboraciones en la revista Teleradio y con trabajos de traducción ${ }^{7}$. Habitualmente, enviaba una crónica

\footnotetext{
${ }^{7}$ Elena Lizón, en discusión con las autoras, 27 de noviembre de 2020.
} 
cada dos o tres días. Las escribía por la tarde, tras leer la prensa portuguesa y escuchar la radio. Por la noche, sintonizaba Radio París "para enterarse de las verdades", según Elena Lizón, quien recuerda que con 11 o 12 años, y en algunas ocasiones, ella misma dictaba las crónicas al taquígrafo de Pueblo cuando sus padres salían por la noche, dado que mantenían una vida social muy activa. Por su condición de corresponsales, eran invitados habituales en las recepciones en Villa Giralda, la residencia de la familia real española, y mantenían numerosos encuentros con escultores, pintores, escritores y artistas hispano-portugueses. Llevaron a cabo una labor de acercamiento cultural entre ambos países que el Gobierno portugués les reconoció en 1964, al condecorarles con la Orden del Infante Dom Enrique de Portugal por su contribución a reforzar los lazos de amistad entre España y Portugal. Guerrero fue la primera mujer extranjera en obtener este galardón. En los ambientes culturales se decía que la verdadera embajada de España era la "casa de los Lizón", por todas las iniciativas culturales que promovían: organización de exposiciones, tertulias literarias...

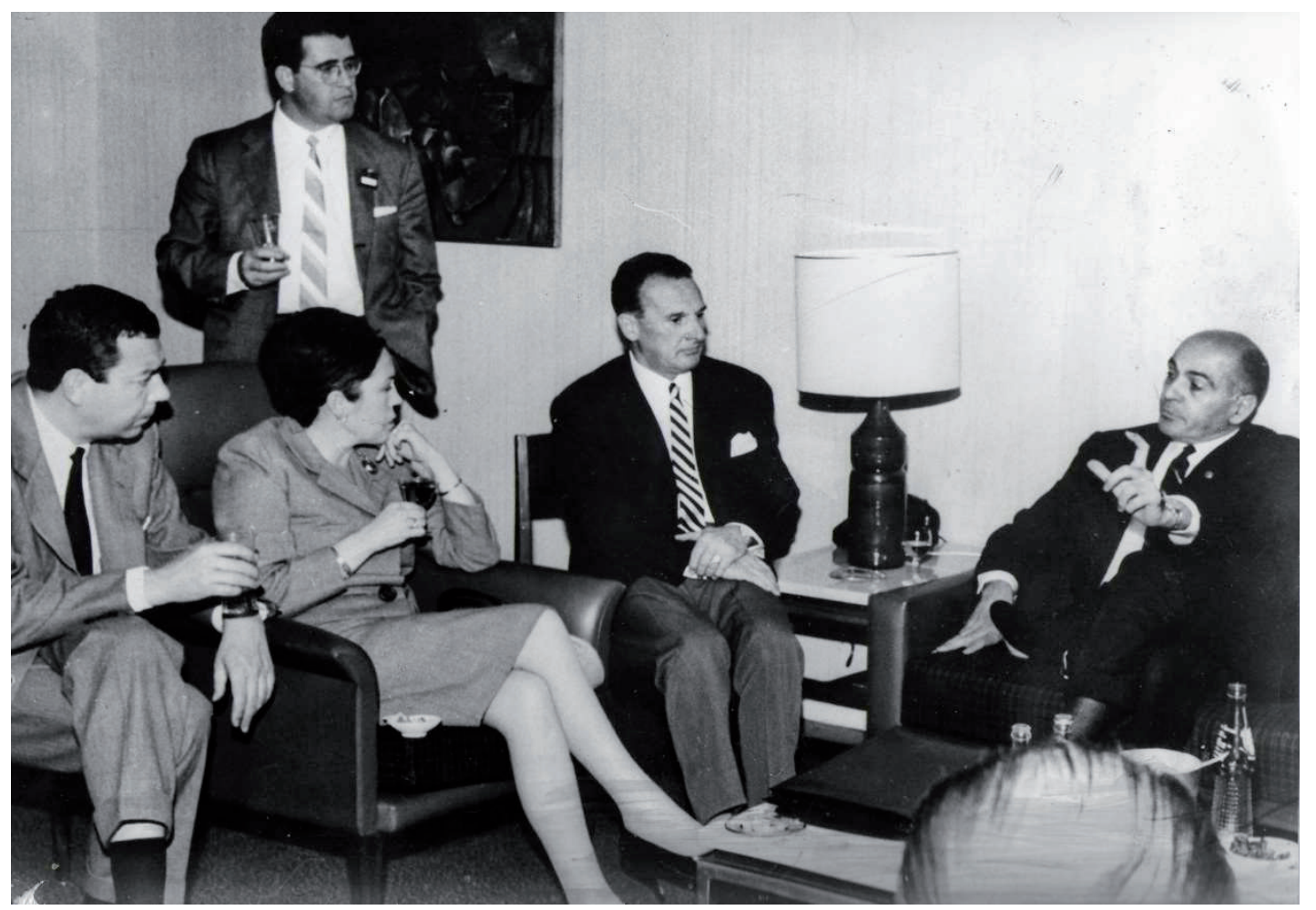

Conchita Guerrero asiste a un encuentro con el ministro Secretario General del Movimiento, José Solís (Archivo familiar).

El año 1964 constituyó un antes y un después en la vida de los periodistas. Adolfo Lizón, junto con un amigo diplomático, descubrió un turbio asunto político-financiero en el que estarían implicadas conocidas personalidades del régimen franquista. Para evitar que saliera a la luz, el entonces embajador de España en Portugal y exministro de Educación Nacional, José Ibáñez Martín, y el agregado de prensa de la Embajada y exdirector de Arriba, Ismael Herráiz, consiguieron que Lizón fuera cesado fulminantemente como 
corresponsal de la agencia Pyresa y como profesor del Instituto Español de Lisboa. No lograron, sin embargo, que Oliveira Salazar expulsara al matrimonio del país, tal y como le pidió el propio Ibáñez Martín. Para oponerse arguyó entonces que eran "grandes

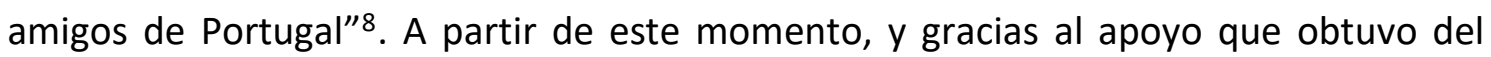
director de Pueblo, Conchita Guerrero incrementó su protagonismo en el periódico. También en el núcleo familiar, pues se convirtió en su sostén económico.

Muy conocida y bien relacionada, ostentó el cargo de vicepresidenta de la Asociación de la Prensa Extranjera en Lisboa. Uno de sus mayores éxitos periodísticos lo consiguió en las navidades de 1969, cuando publicó la última entrevista que se hizo a Salazar antes de su muerte. Como es sabido, en septiembre de 1968, y en vista de que el mandatario portugués no se recuperaba del coma en el que se encontraba como consecuencia de un accidente cerebrovascular, el presidente de la República, Américo Tomaz, comunicó a los portugueses que Salazar no continuaría al frente del Gobierno. Desde aquel anuncio, las escasas informaciones sobre su enfermedad y muerte, ocurrida el 27 de julio de 1970, fueron cuidadosamente controladas por el régimen de censura, por la policía política, la PIDE, y por las decisiones tomadas en un círculo muy restringido que detentaba el poder (Lima, 2017). Poco se supo hasta que el 7 de septiembre de 1969 apareció en L'Aurore la entrevista del periodista Roland Faure a Salazar titulada "Salazar croit qu'il gouverne encore le Portugal...". En ella subrayaba que el expresidente del Consejo vivía con la ilusión de que todavía era el jefe de Gobierno. La interviú, que tuvo una gran repercusión internacional, no pudo leerse en Portugal porque la censura bloqueó los 3.000 ejemplares que habitualmente se distribuían en el país (Castanheira, 2008).

Años más tarde, en 2008, Roland Faure rememoraba este encuentro en el diario portugués Expresso (Castanheira, 2008). Tras reafirmarse en que Salazar vivía una ilusión orquestada por quienes le rodeaban, declaró que, aunque mantenía muchas de sus facultades mentales - seguía hablando francés con fluidez y era consciente de la política internacional-, creía que seguía siendo el jefe de Gobierno, que Marcelo Caetano había vuelto a la universidad a impartir docencia y que Américo Tomaz era su reemplazo temporal.

Estas declaraciones en L'Aurore no fueron, como afirmaba entonces la edición de Expresso, las únicas concedidas por el dictador durante su convalecencia. Fueron posteriores, y por tanto las últimas, las recogidas por Conchita Guerrero el 26 de diciembre de 1969. La periodista pretendió dar respuesta a las preguntas que "con más insistencia e interés - decía- nos hacen en España, cuando llegamos de Portugal: ¿Cómo está Salazar? ¿Vive? ¿Oye? ¿Entiende? ¿Existe de verdad o no?” (Guerrero, 26 de diciembre de 1969). No es descartable que dicha entrevista se hiciera como respuesta a

\footnotetext{
8 Ibídem.
} 
la polvareda levantada por L'Aurore o, incluso, a sugerencia del propio régimen portugués. Indistintamente de las causas que la motivaran, lo cierto es que la pretensión de intentar responder a dichas interrogantes evidenciaba el apagón informativo que rodeaba el estado de salud de Salazar.

La interviú, solicitada telefónicamente por Conchita Guerrero, y a la que acudió Adolfo Lizón por deseo expreso de Salazar, no desvelaba si el exmandatario pensaba que aún gobernaba el país, pero sí que era consciente de que había estado "muy enfermo" y de que su convalecencia transcurría "con lentitud". Conservaba su interés por "las cosas de España", por el "gran hombre y gran amigo", Francisco Franco, y se ratificaba en la política colonialista del Estado Novo en los territorios africanos: "las independencias prematuras son peligrosas". A decir de Conchita Guerrero, "no tuvo en ningún momento pérdida de lucidez", a pesar de que le habían advertido de que Salazar tenía "ratos de vivacidad y ratos de atonía". Elena Lizón evoca las repercusiones de esta publicación:

Tengo unos recuerdos muy precisos de la conmoción de la noticia y del ambiente vivido en casa de mis padres, recibiendo llamadas de agencias y periódicos de medio mundo para preguntar y conocer más detalles. La entrevista causó un gran impacto mediático.

Conchita Guerrero mantuvo una buena relación con quien tomó el relevo a Salazar y se convirtió en el nuevo presidente del Consejo, Marcelo Caetano. Precisamente, en mayo de 1970, con motivo del viaje de Estado que giró a España, Guerrero (19 de mayo de 1970) y Narvión (19 de mayo de 1970) fueron las únicas mujeres periodistas, tanto de España como de Portugal, que firmaron crónicas -desde Lisboa y París, respectivamente- de este acontecimiento (Sanz-Hernando, Cabrera y Baptista, 2020). La corresponsal lisboeta guardó también una cordial relación con el fundador del Partido Socialista en Portugal, Mario Soares. Cuando el activista contra la dictadura portuguesa volvía a la capital y permanecía bajo arresto domiciliario, Elena Lizón acudía a su casa para llevarle, en nombre de su madre, un sobre en cuyo interior iba escrita la cuestión que a la periodista le interesaba que respondiera.

La policía no se fijaba en una niña como yo, así que llevaba el sobre y luego pasaba a recogerlo. En mi casa el teléfono estaba intervenido [...] A pesar de que fueran ideológicamente diferentes, ella le tenía una gran simpatía y mantuvieron el contacto hasta que Soares falleció ${ }^{9}$.

\footnotetext{
${ }^{9}$ Ibídem.
} 


\section{El ocaso de sus carreras}

Tras 20 años de corresponsal, Pilar Narvión pidió volver a Madrid en 1973. Se percató de que con el cambio de década la información internacional había sido relegada a páginas interiores, mientras que eran las noticias nacionales las que copaban las portadas. Pensó que España estaba cambiando. Por entonces, la nómina de mujeres periodistas en las redacciones de los diarios madrileños era aún escasa (García-Albi, 2007), si bien en Pueblo se encontraban ya firmas que luego serían importantes, como Julia Navarro, Rosa Villacastín, Carmen Rigalt y Mercedes Jansa. Narvión fue nombrada jefa de Local, puesto que ocupó por poco tiempo, pues tras la muerte de Franco comenzó su andadura como cronista parlamentaria.

Durante el breve mandato de Pío Cabanillas en el Ministerio de Información y Turismo (enero-octubre de 1974), en la que se considera la etapa más aperturista del régimen de prensa durante el franquismo (Fuentes y Fernández, 1997), a Pilar Narvión se le ofreció la dirección de Pueblo. No aceptó porque debía despedir a la mitad de los profesionales. "Pío Cabanillas quiso darme todos los cargos que había... quiso hacerme directora general de TVE. Cuando yo no quise, se lo dio a Cebrián", reconocía en una entrevista en Radio Nacional de España, donde confesaba que nunca fue amante de los cargos que implicaran gestión o dirección: "Con la máquina de escribir soy capaz de asaltar el Pentágono, pero sin máquina no soy capaz de nada" (Ventero, 2008).

Cuando Naciones Unidas declaró 1975 Año Internacional de la Mujer, Narvión, en su condición de subdirectora de Pueblo, fue incorporada a la Comisión Interministerial, presidida por Pilar Primo de Rivera. Su actividad creó ciertas tensiones con los sectores feministas que encontraban en estos actos conmemorativos la huella ideológica de un tiempo ya superado. Esta efeméride supuso un salto cualitativo y cuantitativo en la lucha feminista en España, así como en su visibilización pública. Sirvió igualmente para que miles de mujeres de toda España se unieran a la causa (Etura y Martín, 2020). La periodista, a quien se calificó entonces de mujer del pasado y exponente de la "derechona" (Díaz-Nosty, 2020) desplegó una gran actividad. Ofreció cerca de 100 conferencias a lo largo y ancho del país, con apariciones en Televisión Española, por lo que se convirtió en un personaje popular y mediático. Aprovechó también las páginas de Pueblo para hablar sobre la cuestión:

Al repasar la lista de los hombres ilustres [...] las mujeres brillan por su ausencia o están en insignificante minoría, salvo en un capítulo, el de santas, vírgenes y mártires, en el que se llevan la palma [...] Reconozcan que en toda santa, virgen y mártir hay una formidable rebelde, y es esa rebeldía la que asume la mujer cuando toma conciencia de una sociedad, injusta para la mujer, en la que vive. (Narvión, 4 de febrero de 1976). 
Durante su última etapa, cubrió desde la Ley para la Reforma Política de 1976 al triunfo del PSOE en las elecciones de 1982, convirtiéndose en una de las cronistas parlamentarias más informadas, perspicaces e irónicas de la Transición (Soriano, 2013).

Ella vivió con pasión la Transición, desde la certeza de que el periodismo tenía un papel muy importante. Hizo todo lo que pudo para que hablaran los unos con los otros [los políticos de diferente signo]. Hubo un contacto muy próximo entre periodistas y políticos, porque estaban metidos en el mismo barco: sacar a España adelante y convertirla en un país democrático ${ }^{10}$.

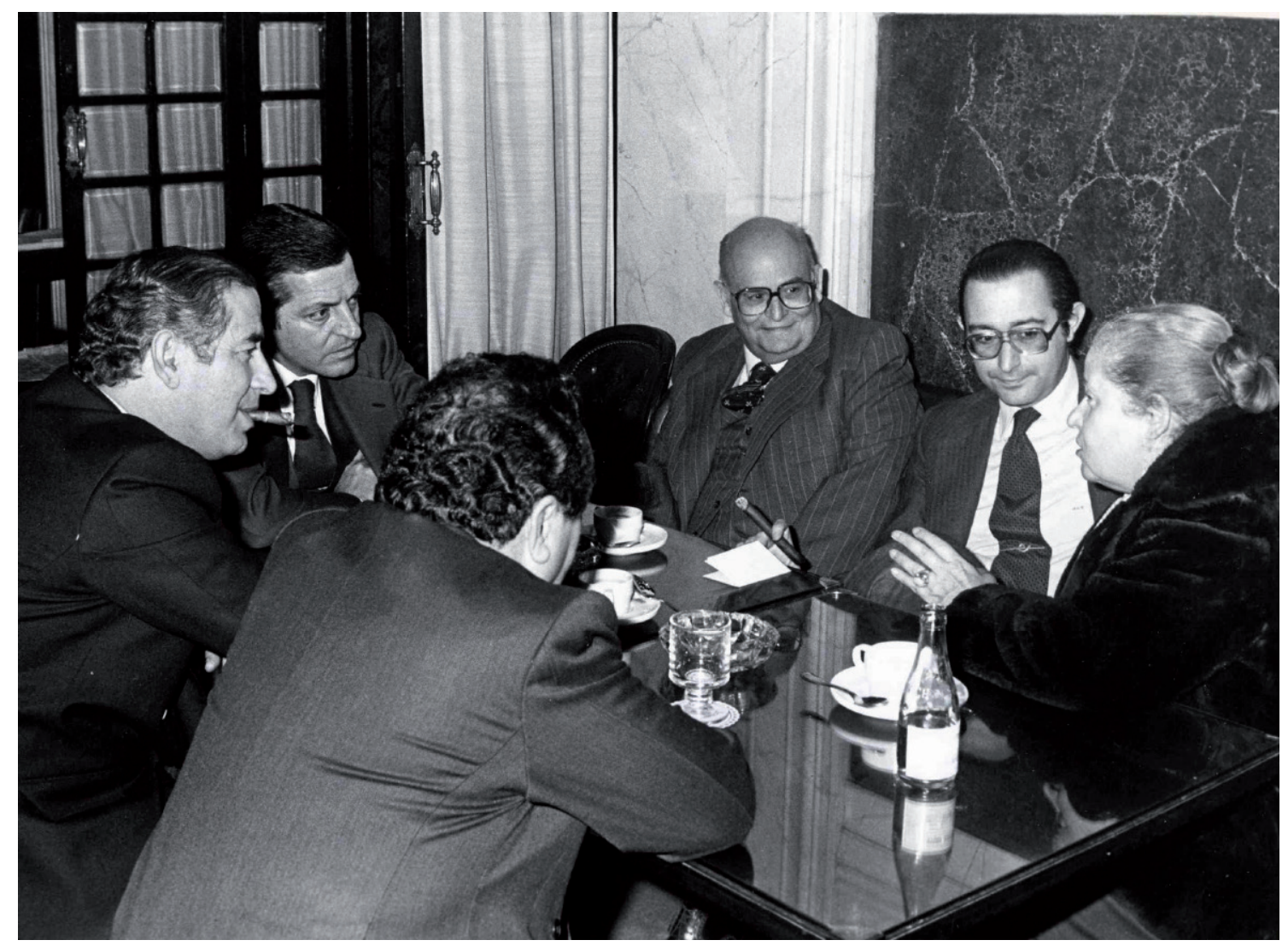

Pilar Narvión con el presidente del Gobierno, Adolfo Suárez, y otros representantes políticos (Archivo familiar).

Alrededor de la veterana periodista se arremolinaron las jóvenes que cubrían la crónica parlamentaria, las conocidas como "las niñas de la Narvión", con quienes mantuvo un lazo muy fuerte y la rejuvenecieron en su forma de hacer periodismo (Soriano, 2008). Cuando el 23 de febrero de 1981 el teniente coronel Antonio Tejero entró en el Congreso de los Diputados a punta de pistola, Pilar Narvión se encontraba rodeada por Julia Navarro, Mercedes Jansa, Rosa Villacastín, Pilar Cernuda, Charo Zarzalejos... a quienes se dirigió con la célebre frase: "Niñas, apuntad la hora, el día y fijaros en lo que está

\footnotetext{
10 Javier Capitán, en discusión con las autoras, 3 de febrero de 2021.
} 
pasando, porque esto es lo que la historia dice que es un golpe de Estado" (Ventero, 2008).

Convencida de que el siglo XXI sería el de "la irrupción de la mujer en el campo de la política", y que ejercería el poder de un modo distinto al hombre, "mucho más acentuado en las preocupaciones sobre la calidad de vida" (Narvión, 5 de octubre de 1981), se jubiló anticipadamente a los 61 años, en 1983, y siendo la primera mujer directora adjunta de periódico. Para entonces, la mitad de la redacción de Pueblo estaba formada por mujeres. Mantuvo una columna diaria hasta que el rotativo cerró en 1984, y colaboró asimismo en el programa de la SER dirigido por Iñaki Gabilondo, "Hoy por hoy". Falleció el 7 de julio de 2013 como consecuencia de un problema cardiaco.

Por lo que se refiere a Conchita Guerrero, regresó a Madrid tras 28 años residiendo en Portugal y 18 años al frente de la corresponsalía. El 1 de noviembre de 1973 se incorporó a la sección de Internacional, causando alta en la plantilla el 1 de noviembre de 1975, con la categoría de Ayudante de Redacción. En noviembre de 1978 pasó a desempeñar las funciones de jefa de Sección en Internacional ${ }^{11}$.

Aprovechando que el 18 de octubre de 1980 la Federación de Asociaciones de la Prensa de España suscribió un acuerdo con la Unión de Periodistas, UGT y CC.OO. para reconocer los derechos adquiridos por quienes hubieran ejercido la profesión y no dispusieran del título oficial de periodista, emprendió los trámites a fin de obtener el carné. Se acogió a la llamada tercera vía, modalidad por la que los no licenciados universitarios, si demostraban haber realizado actividades informativas durante al menos cinco años, podrían acceder a dicho carné ${ }^{12}$. Fue así como en marzo de 1983 ingresó en la Asociación de la Prensa de Madrid y, con efectos de 1 de marzo de 1985, quedó inscrita en el Registro Oficial de Periodistas con el número $11.929^{13}$.

Conchita Guerrero fue feliz trabajando en Pueblo, diario al que consideraba "una escuela de periodistas", y cuyo ambiente le encantaba, a pesar de que su notoriedad era inferior a la de su etapa como corresponsal. Muchas de las informaciones que realizó en este tiempo ya no llevaban estampada su firma. En algunas de las escasas piezas sin autoría que se conservan en el archivo familiar aparece la anotación "esto lo he hecho yo". Siempre hablaba de que era una redacción divertida, con muchos jóvenes. Por eso, le afectó mucho el cierre del periódico.

Debido a que el diario formaba parte del organismo Medios de Comunicación Social del Estado (MCSE), a los periodistas les ofrecieron integrarse en los gabinetes de prensa de

\footnotetext{
${ }^{11}$ Expediente no 4577/1983. Concepción López Guerrero. Asociación de la Prensa de Madrid.

12 Ibídem.

${ }^{13}$ Carta del secretario de la Federación de Asociaciones de la Prensa de España, Álvaro López Alonso, a Concepción López Guerrero. Madrid, 7 de marzo de 1985. Ibídem.
} 
las instituciones públicas. Conchita Guerrero se incorporó al del Ministerio del Interior, dirigido por José Barrionuevo, con quien mantuvo una buena relación. Allí se encontró, no obstante, con un ambiente funcionarial, burocrático y donde sintió que había un clima misógino y de desprecio a las mujeres periodistas. "Esta etapa la vivió muy mal. Iba a trabajar con mucha tristeza", según relata Elena Lizón. Tras jubilarse en 1987, mantuvo hasta el final de sus días una gran lucidez y un extraordinario interés por las noticias y las nuevas generaciones de periodistas. Falleció el 17 de abril de 2020, a los 99 años de edad, como consecuencia de la Covid-19.

\section{Conclusiones}

Las mujeres tuvieron que aceptar una completa subordinación al padre o al marido durante el franquismo. Sobre ellas recayó principalmente la moral reaccionaria que inundó los valores de la nueva sociedad. No fue, desde luego, el contexto propicio para el desarrollo de una vida profesional. Menos aún la de periodista, donde las mujeres constituyeron una rareza en las redacciones de los periódicos hasta la muerte de Franco y la llegada de la Transición. ¿Cómo consiguieron, entonces, Pilar Narvión y Conchita Guerrero abrirse paso en un mundo de hombres? Ha sido esta la principal cuestión que nos hemos ocupado de responder.

Su llegada al periodismo se produjo por la afinidad al régimen de su entorno familiar. Solo así se entiende que Juan Aparicio permitiera a Narvión matricularse fuera de plazo en la Escuela Oficial de Periodismo e incorporarse después a Pueblo, y que Emilio Romero ofreciera a Guerrero la corresponsalía de Lisboa sin previo paso, además, por la Escuela de Periodismo. Dicho esto, y a pesar de la coincidencia que se produce en sus trayectorias profesionales -corresponsales coetáneas que ejercieron en el mismo diario-, lo cierto es que presentan perfiles muy dispares. Mientras que Pilar Narvión tuvo vocación periodística desde niña y luchó por hacerse hueco en este mundo, Guerrero accedió a la profesión por su afición lectora y su gusto por la escritura. También por sus trabajos de transcripción, y en algunos casos de redacción, de las crónicas que firmaba Adolfo Lizón como corresponsal de Pyresa.

Fueron pioneras en el periodismo político, si bien el desempeño de sus funciones les proporcionó un eco diferente. Relataron los pormenores de una misma época, sí, pero mientras que Narvión asistía a hitos históricos que tenían lugar en democracias como la italiana y la francesa, Conchita Guerrero narraba lo que permitía la dictadura portuguesa, donde existían límites a la libertad de información. A estas restricciones se añadía la estrecha vigilancia de la Embajada de España en Lisboa. Recordemos que Lizón, a pesar de ser un hombre del régimen, fue cesado fulminantemente como profesor y corresponsal dos años antes de que entrara en vigor la Ley de Prensa de 1966. La 
contundente medida afectó a la carrera profesional de Guerrero, quien a partir de entonces y gracias al apoyo de Emilio Romero, incrementó su presencia en el vespertino.

La cobertura de acontecimientos internacionales de especial trascendencia otorgó gran notoriedad a Narvión. Su experiencia vital en países democráticos, en entornos de libertad, le proporcionó una visión diferente que volcó en sus informaciones internacionales, sujetas a menor control gubernamental. Sin embargo, sería con su regreso a España cuando se convirtió en la periodista más brillante. Como ella misma decía, tras su periplo por Roma y París llegó "baqueteada” y sabía muy bien lo que daban de sí los debates políticos, de los que dio buena cuenta en sus populares crónicas parlamentarias. La figura de Conchita Guerrero alcanzó menor repercusión en su última etapa en Pueblo. Su adscripción a la sección de Internacional, que ocupaba ya, en relación con las noticias nacionales, una posición secundaria, contribuyó a que su trabajo fuera menos conocido. Asimismo, cabe subrayar el papel de estas precursoras, y en especial de Pilar Narvión, en la apertura de las redacciones a las mujeres periodistas. La alcañizana fue un referente y un modelo a seguir para las nuevas generaciones. Era esta una de las cuestiones que más la enorgullecían.

La cuestión analizada no se agota en esta investigación. A pesar de que el estudio ha cumplido con su objetivo de visibilizar el trabajo de dos pioneras del periodismo, deja abiertas posibilidades para futuras pesquisas, como las relativas a las desigualdades estructurales que históricamente se han venido produciendo entre hombres y mujeres en el ejercicio de la profesión periodística. El recorrido por la igualdad de género sigue siendo difícil y son necesarios abordajes que ayuden a remover obstáculos. Uno de los más preocupantes, y que evidencian diferentes expertos (Subtil, 2000; Torres, 2016), se concreta en la falta de representación femenina en los cargos directivos de los medios de comunicación.

\section{Referencias bibliográficas}

AGUINAGA LÓPEZ, E. DE (1982): Epistemología del ejercicio periodístico. [Tesis doctoral]. Madrid, Ed. de la Universidad Complutense.

BARRERA, C. (1995): "Factores de cambio en el periodismo de la Transición", en Tusell, J. y Soto, A. (coords.), Historia de la transición y consolidación democrática en España (1975-1986) (2), Madrid, UNED, pp. 449-463.

BENITO, Á. (1969): "Libertad de Información y enseñanza del periodismo en la Europa actual” en Nuestro Tiempo, no 183, pp. 223-242. 
BINGHAM, A., EIROA, M., KINNEBROCK, S. y MCCALLUM, C. (2019): “Gender, Media, and Modernity", in Arnold, K., Preston, P. and Kinnebrock, S. (eds.), The Handbook of European Communication History, Nueva Jersey, Wiley Blackwell, pp. 421-435.

CARRASCO ROCAMORA, M. y MORENO SARDÁ, A. (2019): "La visibilidad de la mujer periodista como productora de información. Periodismo en Cataluña 1966-1986", en Cuadrado, J. (ed.), Las huellas del franquismo: pasado y presente, Granada, Comares, pp. 832-855.

CARVALHEIRO, R. y SILVEIRINHA, M. J. (2018): “Género e receção mediática no Estado Novo Mediapolis - Revista de Comunicação", Jornalismo e Espaço Público, n.o 7, pp. 199-213.

CASANOVA, J. (1992): "La sombra del franquismo; ignorar la historia y huir del pasado", en Casanova, J. et. al (eds.), El pasado oculto. Fascismo y violencia en Aragón, 1936-1939, Madrid, Siglo XXI, pp. 1-28.

CASTANHEIRA, J. P. (2 de agosto 2008): "Salazar acreditava que ainda era chefe do Governo", Expresso. Recuperado de http:/ /bit.ly/3cpH3n9

CASTAÑEDA, P. (1994): Carmen de Burgos: Colombine, Madrid, Horas y Horas.

CENARRO, Á. (2017): "La Falange es un modo de ser (mujer): discursos e identidades de género en las publicaciones de la Sección Femenina (1938-1945)", en Historia y Política, no 37, pp. 91-120.

CHAMBERS, D. y STEINER, L. (2010): "The Changing Status of Women Journalists", in Allan, S. (ed.), The Routledge Companion to News and Journalism, London, New York, Routledge, pp. 49-59.

CHULIÁ, E. (2001): El poder y la palabra. Prensa y poder político en las dictaduras. El régimen de Franco ante la prensa y el periodismo, Madrid, Biblioteca Nueva.

DAVARA TORREGO, F. (2005): "Los periódicos españoles en el tardofranquismo. Consecuencias de la nueva Ley de Prensa", en Comunicación y Hombre, no 1, Recuperado de https://bit.ly/3suwyEm

DÍAZ NOSTY, B. (2020): Voces de mujeres. Periodistas españolas del siglo XX, Sevilla, Editorial Renacimiento.

DJERF-PIERRE, M. (2007): "The gender of journalism: the structure and logic of the field in the twentieth century", Nordicom Review. Jubilee Issue, pp. 81-104.

ESTABLIER PÉREZ, H. (2000): Mujer y Feminismo en la narrativa de Carmen de Burgos "Colombine", Almería, Diputación de Almería. 
ETURA, D. y MARTín JIMÉNEZ, V. (2021): “La oposición al franquismo a través de reivindicaciones feministas: el Año Internacional de la Mujer en Televisión Española", Historia Crítica, n. ${ }^{\circ}$ 79, pp. 3-24, doi: 10.7440/histcrit79.2021.01

FUENTES, J. F. y FERNÁNDEZ SEBASTIÁN, J. (1997): Historia del periodismo español: Prensa, política y opinión pública en la España contemporánea, Madrid, Síntesis.

FUSI, J. P. (2012): Historia Mínima de España, Barcelona, Editorial Turner.

GARCÍA-ALBI, I. (2007): Nosotras que contamos. Mujeres periodistas en España, Barcelona, Plaza \& Janés.

GUERRERO, C. (26 de diciembre 1969): “Oliveira Salazar, entrevistado para Pueblo. Las independencias prematuras son peligrosas", Pueblo, pp. 1, 24.

- (19 de mayo 1970): "Perfil humano de un gobernante. Reforma en la continuidad", Pueblo, p. 6.

GUZMÁN, E. DE (1982): Historias de la Prensa, Madrid, Penthalon.

JULIÁ DÍAZ, S. (1999): Un siglo de España. Política y Sociedad, Madrid, Marcial Pons.

KINNEBROCK, S. (2009): "Revisiting Journalism as a Profession in the 19th Century: Empirical Findings on Women Journalists in Central Europe", Communications: The European Journal of Communication Research, no 34 (2), pp. 107-124.

LIMA, H. (2017): "A "queda" de Salazar: a doença e morte do ditador na imprensa portuguesa", en García J. L. et al. (coord.), Salazar, o Estado Novo e os Media, Lisboa, Edições 79, pp. 363-380.

MORADIELLOS, E. (2000): La España de Franco (1939-1975). Política y sociedad, Madrid, Síntesis.

NARVIÓN, P. (19 de mayo 1970): "Bloque Latino", Pueblo, p. 6.

- (4 de febrero 1976): “Extremismo político femenino", Pueblo, p. 3.

- $\quad$ (5 de octubre 1981): “El poder femenino", Pueblo, p. 3.

NÚÑEZ REY, C. (1991): Carmen de Burgos, Colombine \{1867-1932). Biografía y obra literaria [Tesis doctoral]. Madrid, Ed. de la Universidad Complutense.

- (2005): Carmen de Burgos, Colombine, en la Edad de Plata de la cultura española, Sevilla, Fundación José Manuel Lara.

PALOMO, M. P. (2010): “Carmen de Burgos: Una justa recuperación”, Arbor, № 186 (Extra), p. 1. Recuperado de https://bit.ly/2P8yLqP 
PIZARROSO QUINTERO, A. (1989): “Política informativa: información y propaganda (1939-1966)", en Álvarez J. T. et al (eds.), Historia de los medios de comunicación en España. Periodismo, imagen y publicidad (1900-1990), Barcelona, Ariel, pp. 231-249.

- (2010): “El periodismo en el primer tercio del siglo XX", Arbor, № 186, pp. 45-54. doi: 10.3989/arbor.2010.extrajunion3005

RIEFFEL, R. (2003): “La profession de journaliste entre 1950 et 2000”, Hermès, La Revue, $1, \mathrm{n}$ 은, pp. 49-60.

SÁNCHEZ ARANDA, J. J. y BARRERA, C. (1992): Historia del periodismo español. Desde sus orígenes hasta 1975, Pamplona, EUNSA.

SANZ-HERNANDO, C. y MORENO GALLO, M. Á. (2017): “La Voz de Castilla y su ortodoxo alineamiento con la Prensa del Movimiento", Estudios sobre el Mensaje Periodístico, № 23 (2), pp. 1383-1401.

SANZ-HERNANDO, C., CABRERA, A. y BAPTISTA, C. (2020): "Entre la censura y la propaganda: la cobertura de periódicos españoles y portugueses del viaje oficial de Marcelo Caetano a España en 1970", Revista Latina de Comunicación Social, no 77, pp. 73-94. doi: 10.4185/RLCS-2020-1450

SEOANE, M. C. y SAIZ, M. D. (2007): Cuatro siglos de periodismo en España. De los avisos a los periódicos digitales, Madrid, Alianza Editorial.

SORIANO, J. C. (2008): Pilar Narvión. Andanzas de una periodista perezosa, Teruel, Tirwal.

SUBTIL, F. (2000): "As mulheres jornalistas", Biblioteca On-line de Ciências da Comunicação, pp. 1-17. Recuperado de https://bit.ly/3vLHoXG

- (2009): "Anotações sobre o processo de feminização da profissão de jornalista na década de 1990", in Garcia, J. L. (ed.), Estudos sobre os Jornalistas Portugueses: Metamorfoses e Encruzilhadas no Limiar do século XXI, Lisboa, Instituto Ciências Sociais, pp. 93-108.

TORRES FLORES, A. (2016): “Primeras mujeres periodistas de San Sebastián a Cádiz. Los ejemplos de Carmen de Burgos y Josefina Carabias, pioneras en el periodismo y en la radio, respectivamente", RAUDEM. Revista de Estudios de las Mujeres, no 4, pp. 196-211.

VENTERO, M. (director): (8 de noviembre 2008). Vida de una periodista [Audio en podcast]. Recuperado de https://bit.ly/3dfAjr1

VENTURA, I. (2012): As Primeiras Mulheres Repórteres: Portugal, décadas 60 e 70, Lisboa, Tinta da China. 